\title{
Anatomic structure of leaf of some species of Hemerocallis genus
}

\author{
Lyudmila Sedelnikova ${ }^{*}$, and Lina Cheltygmasheva \\ Central Siberian Botanical Garden, SB RAS, 630090 Novosibirsk, Russia
}

\begin{abstract}
This is research of anatomic features of structure of leaf of 4 species of Hemerocallis genus in the conditions of forest-steppe zone of Western Siberia. It is provided the description of upper and lower epidermis, cross section of leaf. It is revealed that the structure of lamina is characterized by xeromesophytic characters. It is mentioned species specificity in arrangement of adaxial and abaxial stomas pursuant thereto leaves of two types of daylily are amphistomatic and hypostomatic. The greatest number of stomas observed on the abaxial part of leaf $(53-72$ pieces per 1 sq.mm). The conductive system of leaf is presented by well developed bunches of collateral type alternating with large pneumatic cavities.
\end{abstract}

\section{Introduction}

Representatives of the genus Hemerocallis L. (daylily, trout lily, Hemerocallidaceae R. Br. family) are perennial polycarpic herbaceous rhizome plants. They are cultivated in botanic gardens worldwide from of old. It is known that culture conditions exert impact on changes of adaptive characters of plants. A leaf is the most plastic vegetative organ and in its structure reflected the ecological adaptation forming under the influence of species habitat conditions [ $1-3]$. The aim is a comparative study of leaf anatomic structure of four species of Hemerocallis genus in the conditions of the forest-steppe zone of Western Siberia.

\section{Material and methods}

The research is performed in the Central Siberian botanic garden of the Siberian Branch of the Russian Academy of Science (Novosibirsk).As objects of research served leaves of 4 species: H. citrina Baroni, H. fulva L., H. middendorfii Trautv. et C. A. Mey., H. minor Mill. The leaves were collected from middle parts of bines at 2017 growing season. Cross sections were prepared by the sliding microtome with the freezing device. Specimens were studied and photographed by Axioskop-40 (Carl Zeiss) microscope with AxioCam MRc-5 color digital cameras of high resolution and the AxioVision 4.8 program. The description of lead anatomical structure was made by the standard techniques [4-6].

\footnotetext{
* Corresponding author: lusedelnikova@yandex.ru
} 


\section{Results and discussion}

The leaves of the studied species were root, linear, sharp at their top, plain, with outstanding ribs, arcuate. The color of lamina varies from light green (H. fulva, H. minor, $H$. middendorfii) to dark green $(H$. citrina). Species differ on their leaves width, among increase in width daylilies were ranked as follows: $H$. minor $(0.7-1 \mathrm{~cm}), H$. middendorfii $(1.8-2.2 \mathrm{~cm})$, H. citrina $(2.5-3 \mathrm{~cm})$, H. fulva $(3-3.5 \mathrm{~cm})$.

The leaves have clear-cut upper (adaxial) and lower (abaxial) parts of lamina. Outside the leaf is covered with the epidermis characterized by compact arrangement of cells, existence of cuticle and stomas. There were noted each of general and individual traits in the structure of epidermal cells for all the species. The projection of the area of epidermal cells is rectangular (H. citrina) and quadrangular and hexagonal (H. fulva, H. minor, $H$. middendorfii), their outlines are rectilinear, their corners in allied borders are sharp and right (H. citrina, $H$. fulva, $H$. minor), more rarely they are roundish and blunt $(H$. middendorfii). There were revealed differences between cells of upper and lower epidermis. On the adaxial part of leaf the epidermis consists of large thin-walled cells, skintight to each other, they are extended, from rectangular to oval form (H. fulva, H. minor, $H$. middendorfii), $H$. citrina differs in more shortened cells with the curved borders. Earlier rectangular cells of the epidermis were noted in H. fulva [7]. The cell sizes are decrease, and cellular membranes are thickening in the direction from median vein to lateral face of lamina. The epidermis on the abaxial part of all the studied species consists of smaller compacted cells with reinforced walls. They are quadrangular or the hexagonal. Existence of larger epidermal cells on the adaxial part of leaf is an attribute of mesophyte plants. It is established that epidermal cells thickness of the adaxial part in the field of midrib (106.4 \pm $11.2-162.2 \pm 14.6$ microns) is $3-4$ times exceed on average thickness of cells of the abaxial part. At the same time, with distance from the center main rib, the thickness of upper epidermal cells is decreasing almost by $2-3$ times. Thickness of abaxial cells decreases by $1.5-2$ times on average. Except $H$. middendorfii, it was noted the identical sizes of adaxial epidermal cells. It was found the difference in the general thickness of leaf about its midrib. The greatest thickness is revealed for $H$. fulva (1245.5 \pm 2.0 microns), the smallest one for $H$. middendorfii ( $851.4 \pm 6.7$ microns). The value of the general thickness of leaf about $3-4$ veins vary in the range from $553.5 \pm 22.2$ (H. middendorfii) to $734.5 \pm$ 26.4 microns (H. minor). Stomas are oval and they are located at epidermal cells junctions. They are distributed by the ranks parallel to longitudinal axis of leaf and they are dip into epidermis. The stomatal apparatus of tetracytic type, guard cells are surrounded with four accessory cells - two of them are lateral ones and other two are polar. Such type is characteristic of monocotyledonous plants. However, some researchers [3, 8] noted the presence of anomocyte type of stomata in daylilies. For $H$. citrina and $H$. minor we were found abaxial and adaxial stomas (amphistomatic leaf). There are more abaxial stomas (tab. 1) that allows reducing leakage of water during transpiration and enhancing gas exchange.

Table 1. Number of stomata per $1 \mathrm{~mm}^{2}$ of leaf surface

\begin{tabular}{|l|c|c|}
\hline \multirow{2}{*}{\multicolumn{1}{|c|}{ Species }} & \multicolumn{2}{|c|}{ stomata per $1 \mathrm{~mm}^{2}$ of leaf surface, pcs. } \\
\cline { 2 - 3 } & \multicolumn{2}{|c|}{$\mathrm{M} \pm \mathrm{m}$} \\
\cline { 2 - 3 } & Upper epidermis & Lower epidermis \\
\hline H. citrina & $42.8 \pm 3.1$ & $59.4 \pm 4.5$ \\
\hline H. fulva & - & $53.0 \pm 4.3$ \\
\hline H. middendorfii & - & $72.5 \pm 5.2$ \\
\hline H. minor & $31.6 \pm 3.3$ & $54.2 \pm 10.3$ \\
\hline
\end{tabular}

Note. $\mathrm{M}$ is the arithmetic mean, $\mathrm{m}$ is the standard error. 
In upper epidermis their number varies from 31 to 42 , and on the lower from 54 to 59 per 1 $\mathrm{mm}^{2}$. Leaves of H. fulva and H. middendorfii are characterized by existence of stomas only on the lower epidermis (hypostomatic leaf). Their number changes in the range from 53 to 72 per $1 \mathrm{~mm}^{2}$, with the greatest dominance for $H$. middendorfii. Submersed stomas and their existence on the both sides of leaf are connected with xerothytic habitat conditions.

All space between the lower and upper epidermis is filled with the mesophyll containing large amount of chloroplasts. It is presented by the spongy cell tissue consisting of rather small, horizontally extended oval cells, adherent to each other. Cells of palisade parenchyma from upper epidermis are single-layered and expressed poorly, in comparison with the data of [3], where the daylilies grew in arid conditions. On the adaxial part of the studied daylilies about midrib there are from 2 ( $H$. fulva, $H$. minor) to 3 rows of parenchyma cells (H. middendorfii, $H$. citrina). On the abaxial part of the majority of species $(H$. minor, $H$. middendorfii, $H$. citrina) there were noted $4-5$ rows, for $H$. fulva there is $5-6$ rows. With distance from the main vein on the lower part of leaf there was observed reduction of parenchyma cells layers down to $2-3$ (H. minor, H. middendorfii, $H$. citrina), except $H$. fulva (4 layers) (see fig.1).

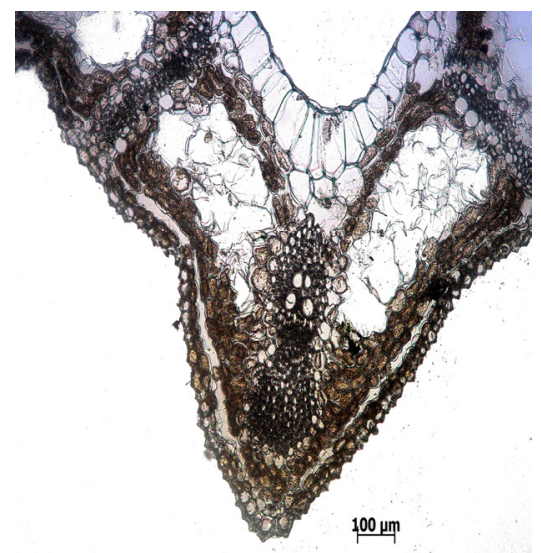

H. middendorfii

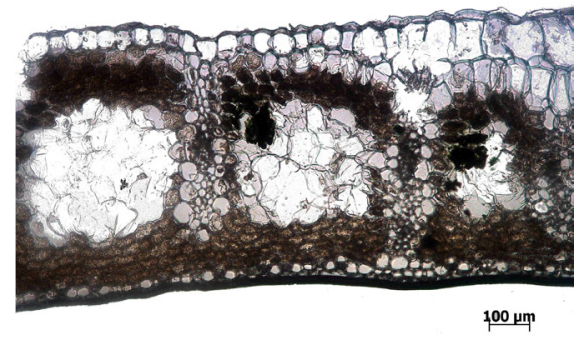

H. fulva

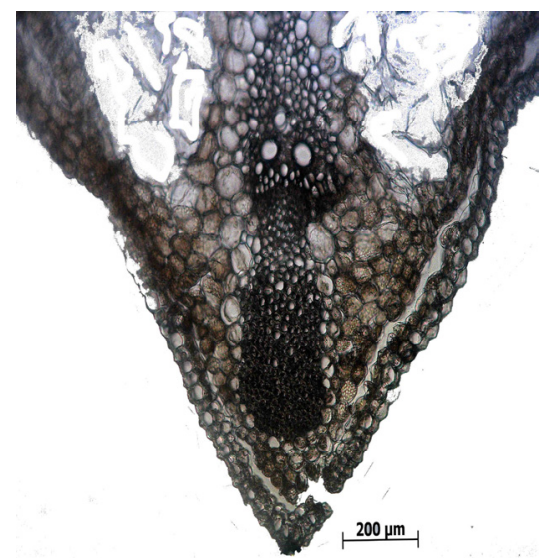

H. minor

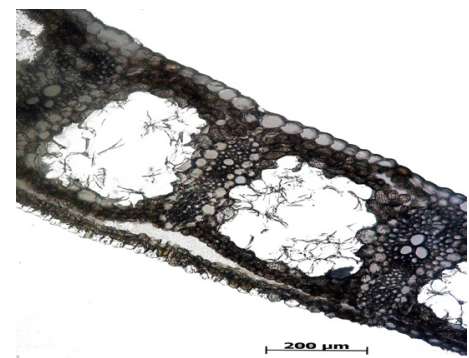

H. citrina

Fig. 1. Anatomical structure of transverse section of Hemerocallis leaf

The leaf mesophyll is penetrated densely by the veins forming uniform conductive system. For all the species there are well-marked central and the side conducting bundles having ordered arrangement in the same row, in parallel each other, at the same time large bunches belong to midrib, and with distance from it to both parts of leaf blade the sizes of conducting bundles are decreasing. In bunches the xylem is oriented to the adaxial party of leaf, and phloem - to abaxial. At such orientation leaf conducting tissues are naturally closed with stalk conducting tissues. Xylem vessels the large and well developed and 
phloem cribriform cells are smaller. Conducting bundles are closed collateral on their type. From the upper and lower parts of conducting bundles are located sclerenchyma parietal cells, which have quadrangular and hexagonal shape and thick membrane. The sclerenchyma protects bunches from mechanical damages and gives durability to leaf blade in general. The conducting bundles alternate with large pneumatic cavities. For different species pneumatic cavities have the different shapes: trapezoid (H. minor) and rectangular ( $H$. fulva, H. middendorfii, $H$. citrina); that was not noted for strains earlier [9]. The arrangement of conducting bundles among mesophyll and pneumatic cavities promotes optimum performance of photosynthetic and transport system. Analysis of our data with literature data [3, $7-9$ ] showed how common features in leaf anatomic structure of Hemerocallidaceae family, and the presence of species features - tetracite type of stomata, mesophytic and xerophytic features. Adaptations in $H$. fulva, H. minor, H. citrina have been revealed, expressed in the quantitative change and structure of mesophyll cells, air cavities, conducting beams in these species under different conditions, which indicates ecological plasticity and the ability to adapt them to wet and dry habitats.

\section{Conclusion}

The studied daylilies possess amphistomatic $(H$. citrina, $H$. minor $)$ and hypostomatic $(H$. fulva, $H$. middendorfii) leaves of dorsoventral type with the well-marked adaxial and abaxial parts. The greatest number of stomas is revealed on the lower epiderma of leaf (53 72 per $1 \mathrm{~mm}^{2}$ ). Conducting bundles are closed collateral; they alternate with large pneumatic cavities. Leaf blades combine mesoxerothytic characters that is connected with their origin, promotes plasticity and well-marked adaptation of the studied species to conditions of forest-steppe zone of Western Siberia.

This work is performed within the state task of the Central Siberian Botanic Garden of the Siberian Branch of the Russian Academy of Science on the project № AAAA-A17-1170126100053-9 "Identification of ways of plants adaptation to contrast habitat conditions at the population and organismal levels". During the preparation for the publishing there were used materials of the CSBS Siberian Branch of the Russian Academy of Science bioresource scientific collection "Collections of live plants on the field and glass-covered ground", UNU № USU 440534.

The authors express their gratitude to A. A. Krasnikov for the methodical help in learning the equipment.

\section{References}

1. Yu.V. Gamaley, Leaf phloem (Nauka, Leningrad, 1990)

2. LF. Hen, PD., Jiang, Y. Wang, HZ. Liu, Northern Horticulture 23, 71 (2011)

3. I.I. Krokhmal, Ecology and Noospherology 23, 41 (2012)

4. E.A. Miroslavov, Structure and function of the epidermis of the leaf of angiosperms (Nauka, Leningrad, 1974)

5. K. Ezau, Anatomy of seed plants (Mir, Moscow, V.2, 1980)

6. CY. Zhou, M. Nie, CD. Yang, Journal of Yangtze University (Natural Science Edition) 3, 44 (2012)

7. W.B. Zomlefer, Harvard Papers in Botany 3, 123 (1998)

8. L.L. Sedelnikova, Vestnik KGAU 7, 55 (2016) 